\title{
Shaken baby syndrome
}

I Blumenthal

Postgrad Med J 2002;78:732-735

Shaken baby syndrome is the most common cause of death or serious neurological injury resulting from child abuse. It is specific to infancy, when children have unique anatomic features. Subdural and retinal haemorrhages are markers of shaking injury. An American radiologist, John Caffey, coined the name whiplash shaken infant syndrome in 1974. It was, however, a British neurosurgeon, Guthkelch who first described shaking as the cause of subdural haemorrhage in infants. Impact was later thought to play a major part in the causation of brain damage. Recently improved neuropathology and imaging techniques have established the cause of brain injury as hypoxic ischaemic encephalopathy. Diffusion weighted magnetic resonance imaging is the most sensitive and specific method of confirming a shaking injury. Families of children with subdural haemorrhages should be thoroughly investigated by social welfare agencies.

Correspondence to: Dr Ivan Blumenthal, Royal Oldham Hospital, Rochdale Road, Oldham $\mathrm{OL} 12 \mathrm{HH}, \mathrm{UK}$ ivan.blumenthal@ norford.fsbusiness.co.uk

Submitted 10 September 2002

Accepted

14 October 2002 n 1860 Tardieu reported thickening of blood on the surface of the brain in Parisian children who were the victims of child abuse. ${ }^{1}$ In 1946 John Caffey, a paediatric radiologist, reported long bone fractures in six infants with subdural haematomas. ${ }^{2}$ A history of injury was lacking and the cause remained unexplained. Nowadays such a scenario would seem incredible, but the phenomenon of child abuse had received little recognition at that time. This changed after Kempe et al highlighted the plight of abused children in their landmark paper in 1962. ${ }^{3}$ In 1971 Guthkelch, a neurosurgeon, reported subdural haematoma as a feature of the "battered child syndrome" and postulated that the brain injury was caused by shaking. ${ }^{4}$ He wrote that the "relatively large head and puny neck muscles" render the infant particularly vulnerable to whiplash injury. Guthkelch also noted that a "good shaking" was felt by British parents to be socially more acceptable and less dangerous than a blow to the head or elsewhere. It is difficult to estimate how frequently infants in Britain are shaken. The incidence of those that come to serious harm can, however, be identified. In two recent British surveys the annual incidence of inflicted subdural haemorrhage was 21.0 and 24.6 per 100000 children under 1 year. ${ }^{56}$ Most children were aged less than 6 months.

Children are usually shaken in response to prolonged inconsolable crying. In a fit of rage the child may also be thrown down. The perpetrator is generally of limited patience and experience in handling a child. Some have admitted using shaking as a technique for stopping the child crying. ${ }^{7}$ Such individuals are most frequently male, fathers, boyfriends, and babysitters. ${ }^{89}$

\section{PATHOPHYSIOLOGY}

The forces needed for a head injury are translational or rotational. Translational forces produce linear movement of the brain. Such forces occur during falls and at worst cause a skull fracture, but are usually relatively benign. Rotational forces, which occur during shaking, cause the brain to turn on its central axis or at the attachment to the brainstem. Movement of the brain within the subdural space causes stretching and tearing of the bridging veins, which extend from the cortex to the dural venous sinus. The loss of blood, typically $2-15 \mathrm{ml}$, into the subdural space is not of itself harmful. ${ }^{7}$ It provides firm evidence of shaking in the absence of a history of severe accidental head trauma.

When an infant is violently shaken the consequent traumatic axonal damage has in the past been described in clinicopathological terms as diffuse axonal injury or axonal shearing. ${ }^{7}{ }^{10}$ Most infants with shaking injury have some clinical, radiological, or pathological evidence of impact." Experimental evidence in both primates and dolls also resolved that the force generated by shaking alone would be insufficient to cause diffuse axonal injury in infants. ${ }^{12-14}$ For these reasons the name originally coined by Caffey, whiplash shaken infant syndrome, has been deemed by some to be an inappropriate description of the injury mechanism. ${ }^{15}$ They would regard shaking impact syndrome as a name more in keeping with the way the injury is caused. ${ }^{11} 16$

In the past decade new information has been gleaned from the use of $\beta$-amyloid precursor protein, the most reliable marker of axonal damage. It has now become possible to distinguish between hypoxic and traumatic axonal injury. ${ }^{17}$ The presence of $\beta$-amyloid precursor protein indicates survival of at least 2-3 hours, a point of medicolegal significance. Contemporaneous with improved methods in neuropathology, imaging techniques in the last decade have advanced and now also enable the distinction between hypoxic and traumatic brain damage to be made. ${ }^{18} 19$ These advances have established that with violent shaking the initial brain injury is caused by hypoxia. ${ }^{17}$ This in turn causes cerebral oedema and raised intracranial pressure. ${ }^{20}$ Further neurological damage or death ensue as a consequence of ischaemia resulting from a fall in cerebral perfusion pressure. The difference between accidental (traumatic) and shaking (hypoxic) injury is well depicted in the difference in outcome. ${ }^{21}{ }^{22}$ In the context of the new information that shaking is 
primarily a hypoxic ischaemic injury, the importance of impact becomes irrelevant. Shown in fig $l$ is the sequence of events causing brain injury.

The initial cause of the hypoxia is respiratory difficulty. Apnoea and breathing problems have been commonly observed in infants who have been shaken. ${ }^{23} 24$ Necropsies on such infants reveal brainstem damage. This damage is unique to infancy, when there is a big head with poor neck muscle tone. The pivotal movement of the head during shaking causes a stretch injury at the craniocervical junction. ${ }^{25}{ }^{26}$ The younger the infant the greater the risk of injury. In very premature infants vigorous physiotherapy without head support can induce histological brain changes of shaking injury identical to that in older infants. ${ }^{27}{ }^{28}$ In infants, unlike older children, the base of the skull is smooth and the unmyelinated brain is soft, resulting in a different pattern of injury. Contusions, superficial foci of haemorrhagic necrosis, which characteristically affect the base of the brain and areas underlying skull fractures, are seldom observed. Infants also frequently have a subarachnoid haemorrhage, which like subdural haemorrhage is small and of little clinical significance. ${ }^{17}$

\section{CLINICAL SIGNS}

There is a wide spectrum of clinical signs. ${ }^{11}{ }^{29}$ The mildest are non-specific so that injury may never be detected; the most severe being the shocked, unconscious, convulsing child. Immediately after the incident the child will always be obviously unwell, even to the most inexperienced carer. The non-specific signs that may persist for days or weeks are poor feeding, vomiting, lethargy, and irritability. These signs are often minimised by doctors and may be attributed to viral illness, feeding problems, or colic. ${ }^{30}$ In some, the signs of previous injury may only be recognised when the child is injured again or presents with a chronic subdural haematoma (head enlargement). It is likely that some children with non-specific signs and undetected brain injury present later with learning difficulty and educational failure.

In the case of a severe injury, it is important to note that unlike an extradural haemorrhage there is no lucid interval between the incident and loss of consciousness. ${ }^{11}{ }^{31-33}$ At presentation the child may be opisthotonic with a full or distended fontanelle. Pallor, hypothermia, and shock are common signs. Apnoea, irregular respiration, and cyanosis necessitate intubation and ventilation.

Children who have been shaken frequently have eye and skeletal injuries.

\section{Eye injuries}

The classic eye sign of inflicted head injury is retinal haemorrhage, which can rarely also occur in severe accidents. Haem-
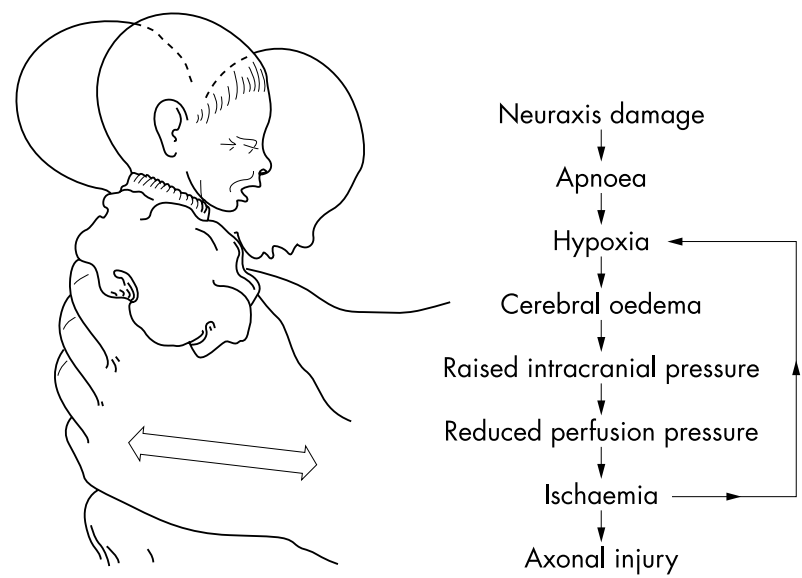

Figure 1 Sequence of events causing brain injury in shaken baby syndrome. orrhages, which may be unilateral or bilateral, confirm the diagnosis of inflicted injury. ${ }^{34}$ Eye haemorrhage without subdural haemorrhage has not been reported, probably because a lesser force is needed to inflict subdural haemorrhage. ${ }^{35}$ The severity of head trauma correlates with the extent of eye haemorrhage. ${ }^{35}$ The first change is intraretinal haemorrhage and subhyaloid haemorrhage, which is followed by retinal detachment and finally choroidal and vitreous haemorrhage. ${ }^{35}$ Haemorrhage at the periphery (ora serrata) is most frequent, but not easily visualised. Most haemorrhage is seen at the posterior pole and can involve one or more layers of the retina. ${ }^{34-36}$ The cause of retinal haemorrhage is not clear. To and fro oscillation of the lens and vitreous causing traction injury where the vitreous is most firmly attached to the retina is one theory, the other being haemorrhage arising from back pressure on the central retinal vein caused by elevated intracranial or intrathoracic pressure. ${ }^{36}$

Neonatal haemorrhage is common and may be a source of confusion. Such haemorrhage usually disappears by eight days but can persist as long as three months. ${ }^{34}$ It is not possible to date retinal haemorrhage by appearance. At necropsy, however, the presence of haemosiderin indicates that the haemorrhage is more than three days old.$^{34}$ With the possible exception of whooping cough, coughing or vomiting do not induce retinal haemorrhage. Neither do cardiopulmonary resuscitation or convulsions. ${ }^{37}{ }^{38}$ Non-traumatic causes of retinal haemorrhage include coagulation and haematological disorders, vasculopathies, and cranial malformations. They can also be caused by meningitis, intracranial hypertension, and some rare metabolic disorders. ${ }^{34}{ }^{36}$ It should be noted that a head injury itself can cause a coagulation abnormality. ${ }^{40}$

\section{Skeletal injuries}

Children with skeletal injuries and subdural haemorrhages were well described by Caffey. ${ }^{25}{ }^{41}$ Metaphyseal fractures, pathognomonic of inflicted injury in infancy, can be caused by damage to the primary spongiosa of the metaphysis as the limbs flail during episodes of shaking. ${ }^{42}$ Squeezing the chest as the child is tightly gripped causes posterior rib fractures. Recent rib fractures might not be immediately apparent on radiography, but can be detected by radionuclide scanning. In the absence of a radionuclide scan, when rib fractures are strongly suspected chest radiography should be repeated after 10-14 days, when callus formation will be evident. ${ }^{42}$ Many infants are given cardiopulmonary resuscitation by paramedical or casualty staff. It should be noted that in infancy cardiopulmonary resuscitation does not cause rib fractures. ${ }^{42}{ }^{43}$

\section{MANAGEMENT, INVESTIGATIONS, AND DIAGNOSIS}

The key principles of management are shown in box 1 . When faced with an unconscious seriously ill infant, in the absence of any explanation, inflicted injury should always be strongly considered. A meticulous examination for evidence of inflicted injury and a skeletal survey should be undertaken. The acute management is exactly the same as for any ill child requiring respiratory support. Social services should be informed immediately so as to protect other children in the family. Early involvement of the police is necessary to facilitate the forensic investigation. The further care of the child may involve a number of hospital specialists and outside agencies. All documentation should be carefully completed and retained for use in possible legal proceedings. Any injuries should be photographed. In the case of a child with a chronic subdural haemorrhage, health visitor and patient held records should be carefully scrutinised. Previous head circumference measurements have been shown to be crucial in identifying the time of the head trauma. ${ }^{44} 45$

A skull radiograph may provide evidence of impact. As fractures heal without callus they cannot be dated. The American Academy of Pediatrics recommends computed tomography 
Box 1: Key principles in emergency management of the unconscious infant when the cause is unknown

- Provide life support.

- Suspect shaking injury.

- Look for retinal haemorrhages and other causes.

- Perform computed tomography when cause remains unknown or retinal haemorrhages seen.

- Inform social services and police if subdural haemorrhage confirmed.

without contrast as the initial investigation of choice to detect a subdural haematoma (fig 2). ${ }^{29}$ It is better than magnetic resonance imaging (MRI) for detection of acute haemorrhage. ${ }^{29}$ Where possible computed tomography should be complemented by MRI 2-3 days later (fig 3). MRI is better at delineating intraparenchymal damage and can be used to distinguish the age of haematomas in the case of repetitious injury ${ }^{46}$ Recently diffusion weighted imaging has assumed an important role in the diagnosis of shaken baby syndrome. ${ }^{18}{ }^{19}$ It demonstrates cerebral ischaemia within minutes of onset and can distinguish between acute and chronic infarction. The changes are apparent before those on conventional computed tomography or MRI. It is now the most sensitive and specific means of identifying shaken baby syndrome. ${ }^{19}$ It is for that reason that it is felt by some that MRI with diffusion weighted sequences should be done at the same time as the initial computed tomogram. ${ }^{19}$

\section{DIFFERENTIAL DIAGNOSIS}

Altogether $95 \%$ of infants with a serious intracranial injury have been shaken. ${ }^{47}$ The remainder are mostly caused by severe head trauma as in motor vehicle accidents. Other conditions that cause subdural haematomas are the same as those which have been listed as causing retinal haemorrhage. About $20 \%-30 \%$ of asymptomatic neonates have small subdural and subarachnoid haemorrhages which rapidly resolve spontaneously. ${ }^{7}$ Rarely, chronic subdural haemorrhage is caused by birth injury. ${ }^{48}$ How often this happens is unknown owing to the difficulty in obtaining a reliable history. ${ }^{45}$

Chronic subdural haematomas develop from small amounts of venous bleeding into an enlarged subdural space. This arises where there is brain atrophy such as in the rare metabolic condition glutaric aciduria type $1 .{ }^{49}{ }^{50}$ It is thought that in this condition the enlarged subdural space causes stretching of the

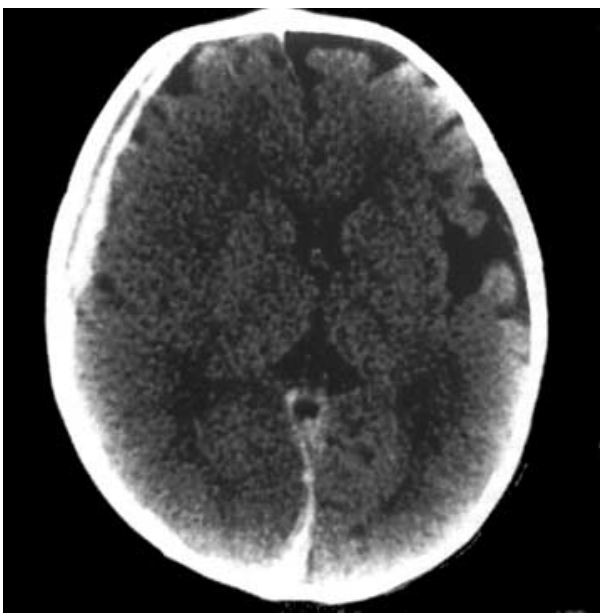

Figure 2 Non-enhanced computed tomogram of a 9 month old infant showing an acute subdural haemorrhage on the right. The child arrived in the casualty department unconscious and having fits. Note the convex shadow and brain swelling on the right with midline shift. bridging veins which tear in response to minimal trauma. An ingrowth of granulation tissue from the dura then forms a vascular membrane with fragile capillaries. Capillary microhaemorrhages maintain the size or enlarge the haematoma. ${ }^{51}$ Other than in children with glutaric aciduria type 1 and ventricular shunts, chronic subdural haematomas should be regarded as inflicted. In glutaric aciduria type 1 frontotemporal atrophy and widening of the sylvian fissure will be apparent on brain imaging. The diagnosis can be made on a biochemical screen and confirmation obtained by the absence of glutaryl-CoA dehydrogenase activity in tissue fibroblasts. ${ }^{49} 50$

It has been suggested that infants with macrocephaly and benign enlargement of the subarachnoid spaces are at risk of developing subdural haemorrhage from minor trauma. ${ }^{52}$ This follows reports in the literature of subdural effusions in children with this benign condition. The fact that prominent subarachnoid spaces are common in infants, and subdural haemorrhage is rare, would indicate that there is no scientific basis for that supposition..$^{53}$ Brain shrinkage, from cellular loss of water in hypernatraemia, has been linked with subdural haemorrhage. An extensive investigation has suggested that hypernatraemia is the consequence of brain injury accompanying subdural haematoma and not the cause. ${ }^{54}$

\section{OUTCOME AND PREVENTION}

It has now been well established that the outcome (morbidity and mortality) of inflicted injury is worse than accidental head injury. ${ }^{21}{ }^{22}$ In the largest case study of inflicted head injury the mortality was $13 \% .{ }^{21}$ The vast majority of survivors of inflicted head injury have some form of neurological or cognitive dysfunction, which may not be fully apparent before 6 years of age. ${ }^{5224335556}$ The neurological outcome parallels the pattern and extent of cerebral infarction resulting from the hypoxic insult. ${ }^{18}{ }^{19}$ An example is occipital lobe involvement which accounts for the high frequency of blindness after inflicted injury. Microcephaly is common, head circumference measurements reflecting a change in brain growth as early as two months after the incident. ${ }^{19}$ In the acute phase diffuse hypodensity on computed tomography or ischaemic changes on diffusion weighted MRI can be used to predict the likely outcome. ${ }^{11} 1819$ Factors strongly related to poor outcome are young age, duration of unconsciousness, and low Glasgow coma scale. ${ }^{22}$

In 1972 while addressing the issue of prevention Caffey wrote $^{41}$ :

"Hark ye, good parents, to my words true and plain,

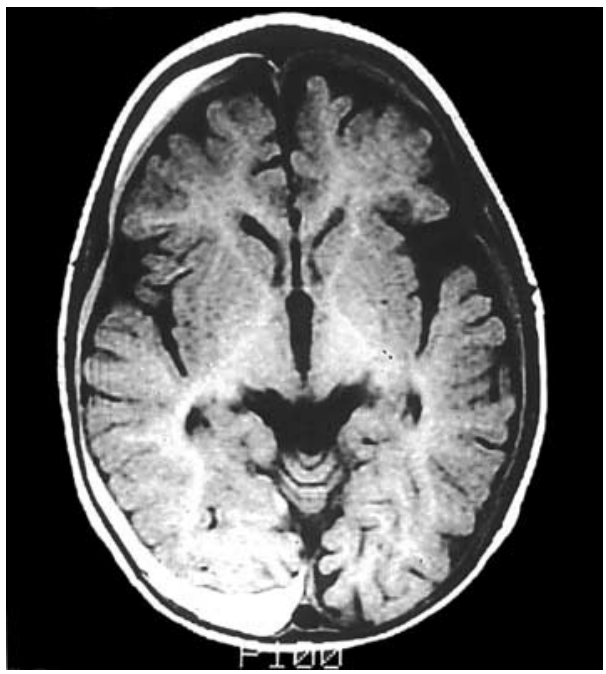

Figure 3 Axial view of MRI T1 weighted image of a 6 month old infant who "fell off a settee". A subdural haemorrhage is apparent on the right. Note the detailed resolution of brain anatomy. 
When you are shaking your baby, you could be bruising his brain.

So, save the limbs, the brain, even the life of your tot;

By shaking him never; never and not".

There has never been a controlled trial showing the effectiveness of a prevention programme. The reason for this is probably the difficulty in establishing the true incidence of shaking in infancy. There is also much public apathy about the subject. In one survey assessing the benefit of a prevention programme directed at mothers, fewer than a third responded..$^{57}$ The high frequency of male perpetrators predicates that an effective prevention programme would need to focus on both men and women. ${ }^{8} 9$ Such a task would be difficult to implement and could be best undertaken through the educational system.

\section{CONCLUSION}

The sequence of events in shaken baby syndrome is initiated by violent whiplash shaking. Cervical hyperextension causes stretch injury to the neuraxis. This produces breathing difficulty or apnoea. The ensuing hypoxia and shock cause hypoxic ischaemic cerebral injury. Further brain damage occurs as a consequence of cerebral oedema, intracranial hypertension, and a fall in cerebral perfusion pressure. In comparison with traumatic injury in infancy, inflicted injury has a much worse prognosis. Subdural and retinal haemorrhage are important markers of shaking injury. The fastest, most sensitive and specific method of determining a shaking injury is diffusion weighted MRI. Where possible this should be undertaken in conjunction with the initial computed tomogram.

\section{REFERENCES}

1 Tardieu A. Etude médico-lègale sur les services et mauvais traitements exerces sur des enfants. Ann Hyg Publ Med Leg 1860;13:361-98.

2 Caffey J. Multiple fractures in the long bones of infants suffering from subdural hematoma. AJR Am J Roentgenol 1946;56:163-73.

3 Kempe CH, Silverman FN, Steele BF, et al. The battered-child syndrome. JAMA 1962;181:17-24.

4 Guthkelch AN. Infantile subdural haematoma and its relationship to whiplash injuries. BM 1971:ii:430-1.

5 Jayawant S, Rawlinson A, Gibbon F, et al. Subdural haemorrhages in infants: population based study. BM 1998;317:1558-61.

6 Barlow K, Minns RA. Annual incidence of shaken impact syndrome in young children. Lancet 2000;356:1571-2.

7 Case M, Graham MA, Handy TC, et al. Position paper on fatal abusive head injuries in infants and young children. Am J Forensic Med Pathol 2001;22:112-22.

8 Starling SP, Holden JR, Jenny C. Abusive head trauma: the relationship of perpetrators to their victims. Pediatrics 1995;95:259-62.

9 Starling SP, Holden JR. Perpetrators of abusive head trauma: a comparison of two geographic populations. South Med J 2000:93:463-5.

10 Geddes JF, Whitwell HL, Graham DI. Traumatic axonal injury: practical issues for diagnosis in medicolegal cases. Neuropathol Appl Neurobiol 2000;26:105-16

11 Duhaime A, Christian CW, Rorke LB, et al. Nonaccidental head injury in infants-the "shaken-baby syndrome". N Engl J Med 1998;338: 1822-9.

12 Gennarelli TA, Thibault $L E$, Adams JH, et al. Diffuse axonal injury and traumatic coma in the primate. Ann Neurol 1982;12:564-74

13 Duhaime A, Gennarelli TA, Thibault LE, et al. The shaken baby syndrome. A clinical, pathological and biomechanical study. J Neurosurg 1987;66:409-15

14 Hanigan WC, Peterson RA, Nius G. Tin ear syndrome: rotational acceleration in pediatric head injuries. Pediatrics 1987:80:618-21.

15 Caffey J. The whiplash shaken infant syndrome: manual shaking by the extremities with whiplash-induced intracranial and intraocular bleedings, linked with residual permanent brain damage and mental retardation. Pediatrics 1974;54:396-403

16 Bruce DA, Zimmerman RA. Shaken impact syndrome. Pediatr Ann 1989;18:482-4.

17 Geddes JF, Hackshaw GH, Vowles CD, et al. Neuropathology of inflicted head injury in children. Brain 2001;124:1290-8.

18 Suh DY, Davis PC, Hopkins KL, et al. Nonaccidental pediatric head injury: diffusion-weighted imaging findings. Neurosurgery 2001;49:309-20

19 Biousse V, Suh DY, Newman NJ, et al. Diffusion-weighted magnetic resonance imaging in shaken baby syndrome. Am J Ophthalmol 2002;133:249-55.

20 Barlow KM, Minns RA. The relation between intracranial pressure and outcome in non-accidental head injury. Dev Med Child Neurol 1999;41:220-5.
21 Reece RM, Sege R. Childhood head injuries. Arch Pediatr Adolesc Med 2000;154:11-5.

22 Prasad MR, Ewing-Cobbs L, Swank PR, et al. Predictors of outcome following traumatic brain injury in young children. Pediatr Neurosurg 2002;36:64-74.

23 Johnson DL, Boal D, Baule R. Role of apnea in nonaccidental head injury. Pediatr Neurosurg 1995;23:305-10.

24 Haviland J, Russell RIR. Outcome after severe non-accidental head injury. Arch Dis Child 1997;77:504-7.

25 Shannon P, Smith CR, Deck J, et al. Axonal injury and the neuropathology of shaken baby syndrome. Acta Neuropathol (Berl) 1998;95:625-31

26 Geddes JF, Vowles GH, Hackshaw AK, et al. Neuropathology of inflicted head injury in children II. Microscopic brain injury in infants. Brain 2001;124:1299-306.

27 Williams AN, Sunderland R. Neonatal shaken baby syndrome: an aetiological view from Down Under. Arch Dis Child Fetal Neonatal Ed 2002;86:F29-F30.

28 Knight DB, Bevan CJ, Harding JE, et al. Chest physiotherapy and porencephalic lesions in very preterm infants. J Paediatr Child Health 2001;37:554-8.

29 American Academy of Pediatrics, Committee on Child Abuse and Neglect. Shaken baby syndrome: rotational cranial injuries. Technical report. Pediatrics 2001;108:206-10.

30 Jenny C, Hymel KP, Ritzen A, et al. Analysis of missed cases of abusive head trauma. JAMA 1999;281:621-6.

31 Gilliland MGF. Interval duration between injury and severe symptoms in nonaccidental head trauma in infants and young children. J Forensic Sci 1998;43:723-5.

32 Willman KY, Bank DE, Senac $M$, et al. Restricting the time of injury in fatal inflicted head injuries. Child Abuse Negl 1997;21:929-40.

33 Gilles EE, Nelson MD. Cerebral complications of nonaccidental head injury in childhood. Pediatr Neurol 1998;19:119-28.

34 The Ophthalmology Working Party. Child abuse and the eye. Eye 1999;13:3-10

35 Green MA, Lieberman G, Milroy CM, et al. Ocular and cerebral trauma in non-accidental injury in infancy: underlying mechanisms and implications for paediatric practice. Br J Ophthalmol 1996;80:282-7.

36 Greenwald MJ. The shaken baby syndrome. Seminars in Ophthalmology 1990;5:202-15.

37 Botash AS, Blatt S, Meguid V. Child abuse and sudden infant death syndrome. Curr Opin Pediatr 1998;10:217-23.

38 Mei-Zahav M Uziel Y, Ginot N, et al Convulsions and retinal haemorrhage: should we look further? Arch Dis Child 2002;86:334-5.

39 Jane D, Kivlin MD. Manifestations of shaken baby syndrome. Current Opinion in Ophthamology 2001;12:158-63.

40 Hymel KP, Abshire TC, Luckey DW, et al. Coagulopathy in pediatric abusive head trauma. Pediatrics 1997;99:371-5.

41 Caffey J. On the theory and practice of shaking infants. Am J Dis Child 1972;124:161-9.

42 Blumenthal I. Child abuse. A handbook for health care practitioners. London: Edward Arnold, 1994: 68-75

43 Spevak MR, Kleinman PK, Belanger PL, et al. Cardiopulmonary resuscitation and rib fractures in infants. A postmortem radiologic-pathologic study. JAMA 1994;272:617-8.

44 Morris MW, Smith S, Cressman J, et al. Evaluation of infants with subdural hematoma who lack external evidence of abuse. Pediatrics 2000;105:549-53

45 Feldman KW, Bethel R, Shugerman RP, et al. The cause of infant and toddler subdural hemorrhage: a prospective study. Pediatrics $2001 ; 108: 636-46$

46 Chabrol B, Decarie J, Fortin G. The role of cranial MRI in identifying patients suffering from child abuse and presenting with unexplained neurological findings. Child Abuse Negl 1999;23:217-28.

47 Billmire ME, Myers PA. Serious head injury in infants: accident or abuse? Pediatrics 1985;75:340-2.

48 Parent AD. Pediatric chronic subdural hematoma: a retrospective comparative analysis. Pediatr Neurosurg 1992;18:266-71.

49 Morris AAM, Hoffman GF, Naughten ER, et al. Annotation, glutaric aciduria and suspected child abuse. Arch Dis Child 1999:80:404-5.

50 Hartley LM, Khwaja OS, Verity CM. Glutaric aciduria type 1 and nonaccidental head injury. Pediatrics 2001;107:174-6.

51 Lee KS, Bae WK, Doh JW, et al. Origin of chronic subdural haematoma and relation to traumatic subdural lesions. Brain Inj 1998;12:901-10.

52 Piatt JH. A piffall in the diagnosis of child abuse: external hydrocephalus, subdural hematoma and retinal hemorrhages. Nerosurgery Focus 1999;7(4) (available at http:// www.neurosurgery.org/journals/online_j/oct99/7-4-4.html).

53 Kleinman PK. Head trauma: extra-skeletal trauma and miscellaneous conditions. Diagnostic imaging of child abuse. 2 nd Ed. St Louis, MO: Mosby, 1998: 312-3.

54 Handy TC, Hanzlick R, Shields LB, et al. Hypernatremia and subdural hematoma in the pediatric age group: is there a causal relationship? J Forensic Sci 1999;44: $1114-8$.

55 Bonnier C, Nassogne M, Evrard P. Outcome and prognosis of whiplash shaken infant syndrome; late consequences after a symptom-free interval. Dev Med Child Neurol 1995;37:943-56.

56 Ewing-Cobbs L, Kramer L, Prasad M, et al. Neuroimaging, physical, and developmental findings after inflicted and noninflicted traumatic brain injury in young children. Pediatrics 1998;102:300-7.

57 Showers J. "Don't shake the baby": the effectiveness of a prevention program. Child Abuse Negl 1992;16:1 1-8. 